\title{
The Design of Intelligent Soybean Milk Machine Control System Dai Junfeng ${ }^{1,}$, , Fu Li-hui ${ }^{2, b}$ \\ ${ }^{1}$ Faculty of Electronic Information Engineering,Huaiyin Institute of Technology, Jiangsu Huaian,223003, China \\ ${ }^{2}$ Faculty of Automation,Huaiyin Institute of Technology,Jiangsu Huaian,223003,China aemail: djf0495_cn@163.com, bemail:flh3650326@163.com
}

Key words: MCU, intelligent soybean milk machine, timing, control system

Abstract: The design is based on control system of 51 series MCU intelligent soybean milk machine. The soybean milk machine can set the timing of making soybean milk and selectively make soybean milk with beans, coarse cereals, vegetables and fruits. The whole system has multiple functions such as detection of lack of water, automatic pulping, anti overflow detection, alarm and automatic heat preservation. The hardware circuit of the system includes ten parts, namely, MCU main control module, power module, water-level detection module, anti overflow detection module, temperature detection module, heating module, pulping module, alarm module, display module, and keyboard module. The system program is realized through assembly language to make the control system of the soybean milk machine have a relatively high intelligent level and a better application prospect and higher value in use on the basis of the effective combination of software and hardware.

\section{The overall system structure}

The system is composed of key module, power supply module,water level detection module,overflow detection module,temperature detection module,heating module,beating module,alarm module and display module, wherein,the key module is used for setting the type of production, current time, timing pulping,the water level detection module is used for detecting whether there is enough water to pulp, and alarm while water is shortage, at the same time,detect if overflow the highest level during the heating process, and active defoaming begin while overflow.The temperature detection module is used for temperature monitoring,the heating and beating module is used for heating and beating, the alarm module is pulping reminder after completion, the displayer is used to display the time and heating temperature, LED is used to show the normal operation of soybean milk machine.

\section{The water level detection and anti overflow detection module}

The water level detection and anti overflow detection circuit is shown in fig.1.

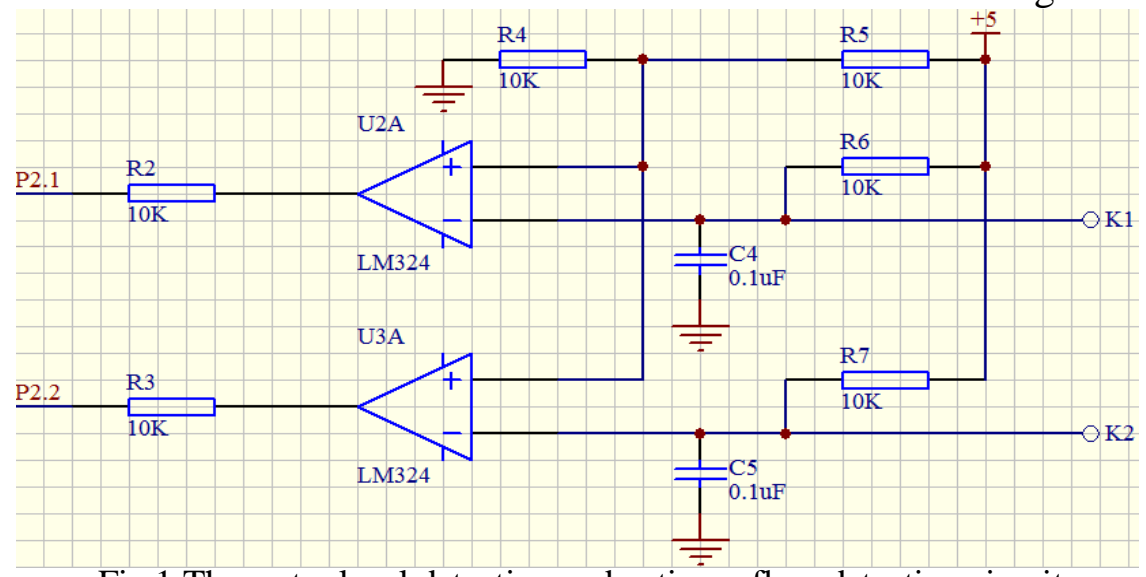

Fig.1 The water level detection and anti overflow detection circuit

In Fig.1, the output of the water level detection circuit is connected with the P2.1 port of the singlechip, and the output of the anti overflow detection circuit is connected with the P2.2 port of the singlechip. The water level detection and anti overflow detection circuit is mainly composed of 
$\mathrm{R} 2, \mathrm{R} 3, \mathrm{R} 4, \mathrm{R} 5, \mathrm{R} 6, \mathrm{R} 7, \mathrm{C} 4, \mathrm{C} 5, \mathrm{~K} 1, \mathrm{~K} 2$ and voltage comparator U2A and U3A, thereinto, K1 is the detection electrode of water shortage, $\mathrm{K} 2$ is the anti overflow detection electrode.

When the water lever did not reach the $\mathrm{K} 1$ electrode, the resistance between $\mathrm{K} 1$ and the earth is relatively large, $\mathrm{K} 1$ and $+5 \mathrm{~V}$ directly connect, so the negative terminal voltage of voltage comparator is $5 \mathrm{~V}$, because the partial pressure of $\mathrm{R} 4$ and $\mathrm{R} 5$ is $+5 \mathrm{~V}$, so the positive side voltage is $2.5 \mathrm{~V}$, the negative side voltage of comparator is greater than the positive terminal voltage, the comparator output low level which indicate water shortage of soybean milk water machine.

When the water level did not reach the K1 electrode, the resistance between K1 and and the earth is lesser, thus the negative side of voltage comparator is low, and the positive side is always $2.5 \mathrm{~V}$, so that the positive side of voltage comparator is greater than the negative side, the voltage comparator output high level which indicate that no water shortage of soybean milk water machine.

Similarly,the whole working principle of K1 electrode is the same with K2 electrode.

\section{The temperature detection design}

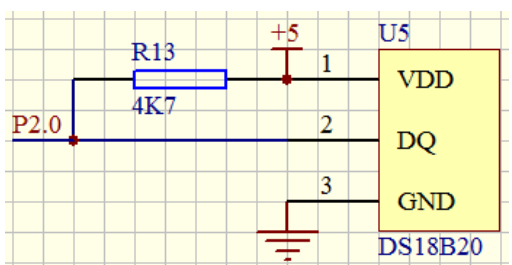

Fig. 2 the circuit of temperature sensor DS18B20

The temperature sensor DS18B20 circuit is shown in fig.2. among,VDD terminal is connected to $+5 \mathrm{~V}$, DQ terminal is connected to the P2.0 port of microcontroller, R13 resistor is used to improve the stability.In the normal operation of soybean milk machine, it need to preheat to 80 degrees for water.The temperature sensitive element in DS18B20 is used to detect the temperature, and convert the temperature value to binary form which stored in the cache memory.

\section{The beating module design}

The beating circuit is an important module design of intelligent soybean milk machine.The beating motor is a single-phase series motor in this design, as shown in fig.3.

This design uses intermittent beating method which can grind soybean milk better,in order to prevent the motor'damage due to continuous work, it add a defoaming device, the defoaming device is two metal rods. When soybean milk boiling, level detection device detects the liquid level exceed the highest level, andd the speed of beating motor reduce, the defoaming device begin defoam.

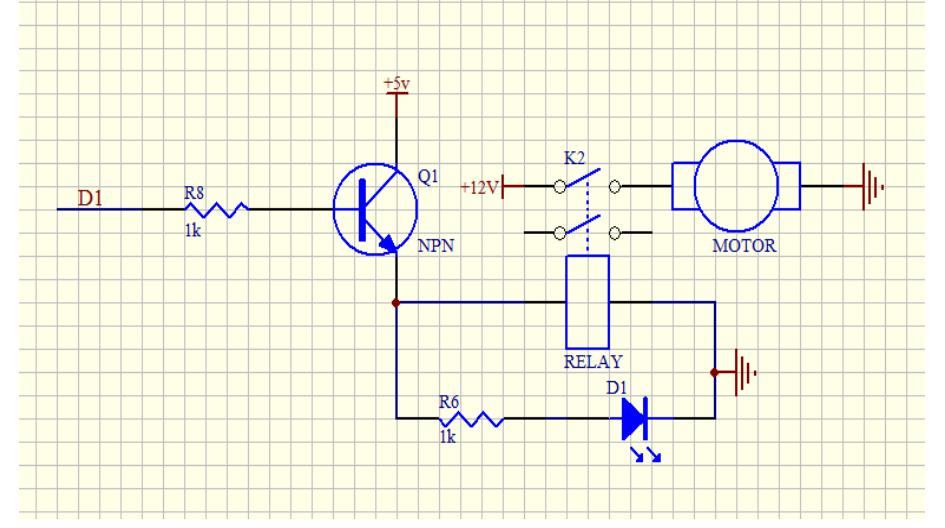

Fig. 3 The diagram of single phase series motor

\section{The heating circuit module design}

The role of the heating circuit is to heat the whole system, the design uses 5 watts heating pipe, the circuit shown in fig. 4 . 


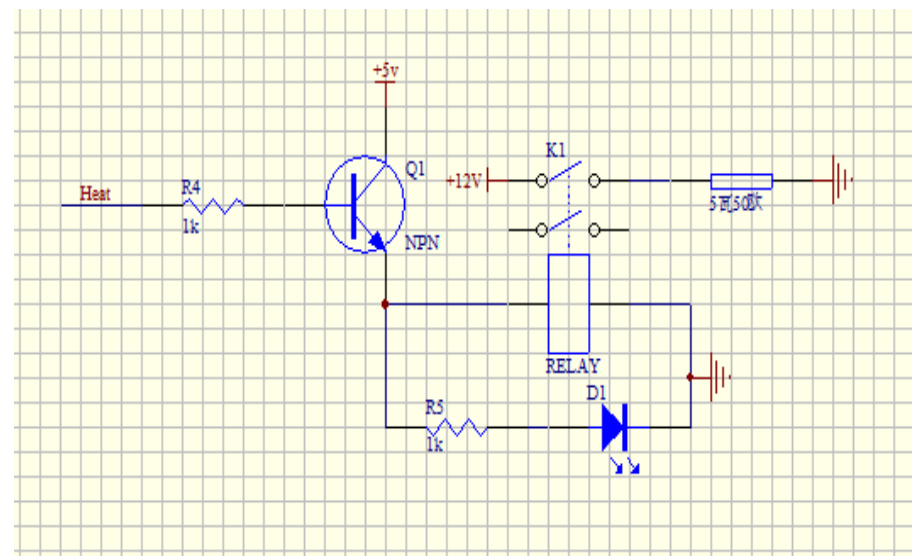

Fig. 4 The diagram of heating circuit

\section{The alarm module circuit design}

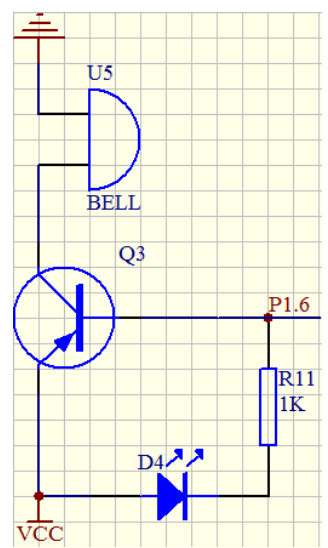

Fig.5 The sound and light alarm circuit

The alarm circuit diagram shown in fig.5, sound and light alarm circuit is mainly composed of buzzer U5, triode Q3, led D4 and resistance R11. When the water is shortage or pulping completed, P1.6 port output low level,D4 alarm lamp began to work at the same time, the triode Q3 start conduction and the buzzer alarm.

\section{The LED display circuit design}

The LED display circuit shown in fig.6.

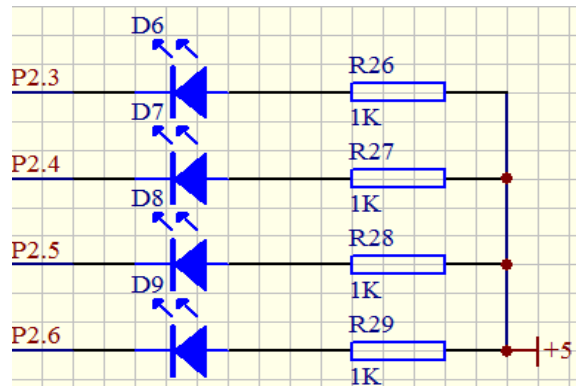

Fig.6 The LED display circuit

The LED display circuit is composed of D6, D7, D8, D9,R26, R27, R28,R29,among,D6 is the indicator lamp of boiled soybean milk and D7 is the indicator lamp of boiled rice paste,D8 is the indicator lamp of fruits and vegetables making,D9 is the indicator lamp of heat preservation. 


\section{The software overview}

When the soybean milk machine is power on,each module is initialized,the keyboard start scan,then,it detect the water level,if the water level is lower than the lowest water level,the sound and light alarm start work to remind adding water,the alarm will stop while it reach the lowest level,in order to ensure the normal operation of soybean milk machine, after that, the microcontroller output a signal to drive the heating module, at the same time,the temperature detection module work, it monitor the temperature of soybean milk machine by the DS18B20 sensor,once the water temperature reache $80 \square$, the beating module start work and the heating module is closed.

After beating,the heating module start cooking,in the cooking process, the water level may exceed the anti-overflow water level,then the detection module output a signal to suspend the heating module operation, and the motor start to defoaming, after the cooking is completed, the sound and light alarm start work,the soymilk machine get into the insulation mode,so far, the design of all the work flow is over.

\section{summary}

The design uses AT89S52 single-chip microcomputer as its control core which is an intelligent control system. Software of this system includes main program,temperature subprogram, liquid crystal display,soybean milk beating subprogram,juice beating subprogram, rice paste beating subprogram,soybean milk boiling subprogram,juice boiling subprogram and rice paste boiling subprogram,etc.Realize intelligent control of soybean milk machine by efficient combination of software and hardware. The operation of soybean milk machine is simple,convenient and practical,it could meet the needs of the function of soybean milk machine.

\section{Reference}

[1]ZOU Yu,WANG Cheng.Nios II processor-based system design multi-function counter.Manufacturing automation, 2011,33(8):146-149

[2]Yiannacouras,P.Steffan,J.G.Rose.Exploration and Customization of FPGA-Based Soft Processors[J].Computer-Aided Design of Integrated Circuits and Systems, 2007,26(2): 266-277

[3]Zhang jie,liu ping.Design and implementation of intelligent access contrlller.modern electronics technique, 2012,35(14):14-15

[4]LAI Guo-jun,XU Ping.Access Control System Based on Ethernet Technology.Journal of the Academy of Equipment Command \& Technology,2003,14(5):81-84

[5]LIU Ming-kun,CHEN Hong-yan,Design of Anti-theft Alarm System Based on Multi-sensor Fusion Technology.Coal Technology, 2012,31(1):134-135 